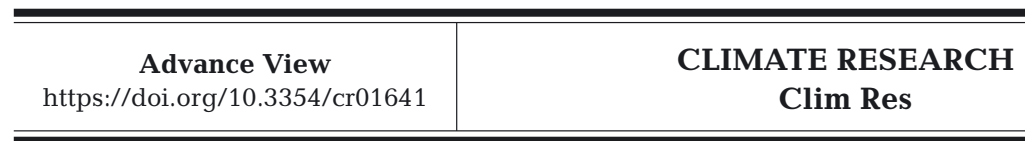

Contribution to CR Special 'Sustainable management of renewable resources in a changing environment: an integrated approach across terrestrial, freshwater and marine ecosystems'

\title{
Spatiotemporal variation in climatic conditions across ecosystems
}

\author{
Ivar Herfindal ${ }^{1, *}$, Sondre Aanes ${ }^{2}$, Rasmus Benestad ${ }^{3}$, Anders G. Finstad ${ }^{4}$, \\ Are Salthaug ${ }^{5}$, Nils Chr. Stenseth ${ }^{6}$, Bernt-Erik Sæther ${ }^{1}$ \\ ${ }^{1}$ Centre for Biodiversity Dynamics, Department of Biology, Norwegian University of Science and Technology, \\ 7491 Trondheim, Norway \\ ${ }^{2}$ Norwegian Computing Centre, 0314 Oslo, Norway \\ ${ }^{3}$ The Norwegian Meteorological Institute, 0313 Oslo, Norway \\ ${ }^{4}$ Centre for Biodiversity Dynamics, Department of Natural History, NTNU University Museum, 7491 Trondheim, Norway \\ ${ }^{5}$ Institute of Marine Research, 5817 Bergen, Norway \\ ${ }^{6}$ Centre for Ecological and Evolutionary Synthesis, Department of Biosciences, University of Oslo, 0316 Oslo, Norway
}

\begin{abstract}
Environmental variation in time and space affects biological processes such as extinction risk and speed of adaptation to environmental change. The spatial structure of environmental variation may vary among ecosystems, for instance due to differences in the flow of nutrients, genes and individuals. However, inferences about ecosystem spatial scale should also include spatial autocorrelation in environmental stochasticity, such as fluctuations in weather or climate. We used spatially structured time series (19-36 yr) on temperature from 4 different ecosystems (terrestrial, limnic, coastal sea and open ocean) to assess the spatiotemporal patterns of environmental variation over large geographical scales (up to $1900 \mathrm{~km}$ ) during summer and winter. The distance of positive spatial autocorrelation in mean temperature was greatest for the terrestrial system (range: 592-622 km), and shorter for the open ocean (range: 472-414 km), coastal sea (range: 155-814 km) and the limnic systems (range: 51-324 km), suggesting a stronger spatial structure in environmental variation in the terrestrial system. The terrestrial system had high spatial synchrony in temperature (mean correlation: winter $=0.82$, summer $=0.66$ ) with a great spatial scaling $(>650 \mathrm{~km})$. Consequently, populations of terrestrial species experience similar environmental fluctuations even at distances up to $1000 \mathrm{~km}$, compared to species in the aquatic systems $(<500 \mathrm{~km})$. There were clear seasonal differences in environmental synchrony in the terrestrial and limnic systems, but less so in the other systems. Our results suggest that biological processes affected by environmental stochasticity occur at the largest spatial scale in terrestrial systems, but their magnitude depends on whether the process is affected by winter or summer conditions.
\end{abstract}

KEY WORDS: Ecosystem - Synchrony - Spatio-temporal autocorrelation - Temperature · Spatial scales $\cdot$ Marine $\cdot$ Terrestrial $\cdot$ Limnic

\section{INTRODUCTION}

Environmental variation in time and space is the main driver affecting processes of ecological and evolutionary change, including population dynamics, ecosystem change, evolution and speciation. Ac-

*Corresponding author: ivar.herfindal@ntnu.no cordingly, both the temporal (Steele 1985, Steele \& Henderson 1994, Messié \& Chavez 2012) and spatial (Moran 1953, Post \& Forchhammer 2002, Liebhold et al. 2004, Bellier et al. 2014, Dembkowski et al. 2016, Frank et al. 2016) scales of ecological and evolutionary patterns and processes causing biological change

( ) The authors 2021. Open Access under Creative Commons by Attribution Licence. Use, distribution and reproduction are unrestricted. Authors and original publication must be credited. 
correspond closely to those of the environment. Accordingly, a thorough understanding of such spatiotemporal environmental dynamics is pivotal in order to predict spatial patterns of ecological and evolutionary processes and dynamics. This is particularly true in the face of the increasing human impact on ecosystems where the need for management and conservation actions at appropriate spatial scales is challenged by decreasing access to natural habitats (Moore et al. 2010, Knapp et al. 2017, Brennan et al. 2019).

Ecosystems vary in the temporal and spatial scale of environmental and biological processes (Cole et al. 1991, Powell \& Steele 1995). The recognition that open aquatic systems have a higher potential for dispersal and migration, and flow of nutrients or other components, than most terrestrial systems (Myers et al. 1997, Carr et al. 2003), has led to the perception that 'blue' marine systems have a greater temporal and spatial scaling of biological patterns and processes than 'green' terrestrial systems (Mayr 1954, Steele 1991, Carr et al. 2003, Vasseur \& Yodzis 2004). These intrinsic physical factors are unquestionably important for processes affecting both population dynamics and gene flow. However, both theory (Frank 2005) and a large body of empirical studies (e.g. Steen et al. 1996, Myers et al. 1997, Stenseth et al. 1999, Jones et al. 2003, Tack et al. 2015) suggest that the spatial scale of environmental variation, such as weather or climate, is at least as important as flow of genes or individuals for stochastic ecological and evolutionary processes. It is therefore also necessary to consider the spatial structure of environmental variation when assessing the spatial scale of biological processes. For instance, regional extinction rates are related to how much dynamics of local populations are synchronised (Heino et al. 1997, Liebhold et al. 2004). If environmental stochasticity affecting population growth is synchronised over great spatial scales, the fluctuations in population abundances will be synchronised accordingly (Moran 1953), which may have cascading ecosystem effects (Elton 1924). Still, a thorough evaluation of spatial structure of such environmental stochasticity across systems is rarely done in comparative studies (Hansen et al. 2020).

Sensitivity to environmental variation varies among species (Bjørkvoll et al. 2012, Sæther et al. 2013), and accordingly, the synchronising effect of the environment on population dynamics can differ among species (Marquez et al. 2019). Often this variation can be related to the fast-slow continuum of life histories (Oli 2004). Because the dynamics of species with fast and slow life histories are affected mainly by repro- duction and adult mortality, respectively (Oli 2004), the spatial structure of the environmental variation affecting population dynamics may differ. This occurs because reproduction and adult mortality often occur in different parts of the year, which in temperate and boreal regions is typically summer and winter, respectively. Accordingly, any seasonal difference in the spatial scaling of environmental conditions can lead to species-specific patterns in their spatial structure of ecological and evolutionary processes. Such differences may also occur if the same life history event (e.g. breeding) occurs at different times, even if the different species inhabit the same area, which is the case for many marine fish species (Olsen et al. 2010). Consequently, the spatial structure of environmental variation must be related to the critical period of a species (Sæether et al. 1996), which further emphasises the need for detailed empirical assessment of system-specific environmental scaling (Mokany et al. 2010).

Here we describe the spatial properties (patterns of spatial autocorrelation and scale of synchrony; Walter et al. 2017) of environmental variation in 4 systems: terrestrial, limnic, coastal sea and open ocean. These systems differ considerably in biological and physical characteristics (Steele 1985, Cole et al. 1991, Steele \& Henderson 1994, Carr et al. 2003); however, they experience much of the same challenges with respect to biodiversity threats due to human activity (Carr et al. 2003, Brondizio et al. 2019). We used spatially structured long-term data on temperature to compare the spatial structure of environmental variation between these systems. Temperature is one of the most important environmental variables affecting individual growth, reproduction and survival in species across all taxa (Clarke 2017). Accordingly, all species have lower and upper thermal bounds (the thermal niche), and conditions outside these thermally viable envelopes will reduce fitness and population growth (Deutsch et al. 2008, Tewksbury et al. 2008). Knowing the patterns of spatiotemporal variation in temperature across ecosystems may thus be a first step to assess general patterns of the spatial scale of biological processes.

\section{MATERIALS AND METHODS}

\subsection{Data}

Daily mean temperature from weather stations in Norway and Sweden were downloaded from the European Climate Assessment database (Klein Tank 
et al. 2002). We excluded stations on remote islands. The daily temperatures were aggregated to mean temperature during winter (February-March) and summer (July-August) per station and year. The total number of stations with at least $10 \mathrm{yr}$ of data were 156 for both summer and winter seasons (Fig. 1).

Data on water temperature from Norwegian lakes were obtained from the Norwegian Water Resources and Energy Directorate (NVE) and from Swedish lakes from the Swedish University of Agricultural Sciences database for Swedish lakes and watercourses (http://miljodata.slu.se/mvm/, in Swedish). These data were collected at different depths which were classified into $1 \mathrm{~m}$ (surface to $1 \mathrm{~m}), 2 \mathrm{~m}(1-2 \mathrm{~m}$ ), $5 \mathrm{~m}(2-5 \mathrm{~m})$ and $15 \mathrm{~m}(5-15 \mathrm{~m})$ depth bins. The data were often sampled at short intervals, mainly during the months February, March and July-August. For each station, we calculated the seasonal mean value per year (same definition of seasons as above). The total number of stations with sufficient length of the time series (at least $10 \mathrm{yr}$ ) for summer and winter were 134 and 80, respectively, with fewer locations for the $15 \mathrm{~m}$ depth class.

For the coastal areas, sea temperature was obtained from 9 stations along the Norwegian coast from the Institute of Marine Research in Norway (Aure \& Østensen 1993, Sætre et al. 2003). Daily sea temperature was available from the following depths: $0.5,50,100$ and $300 \mathrm{~m}$. Data were aggregated to seasonal (see above) averages per year per depth. All stations had data from both summer and winter at all depth classes, except the $300 \mathrm{~m}$ depth (8 stations).

Since the $1970 \mathrm{~s}$, the Institute of Marine Research in Norway has conducted different annual surveys in the Barents sea where temperatures have been measured systematically at different depths using CTD casts (see e.g. Jakobsen et al. 1997, Stiansen \& Filin 2007). The samples are approximately uniformly distributed in space, although the positions of these stations have not been constant between years. Sea temperature was categorised in depth groups as follows: surface $(0-5 \mathrm{~m}) ; 50(30-75 \mathrm{~m})$; $100(75-150 \mathrm{~m}) ; 200(150-250) ; 300$
(250-350 m). Because the locations were not exactly the same from year to year, we aggregated locations based on a stratified grid of equal area hexagons $\left(\right.$ size $=8100 \mathrm{~km}^{2}$, see Fig. 1 and Marquez et al. 2019). Temperature was then aggregated by season (see above) and depth class within each hexagon. The number of hexagons with temperature data (minimum $10 \mathrm{yr}$ ) during summer and winter was 72 and 60, respectively, but somewhat lower for the deepest depth class.

Hereafter, we refer to the spatial location of the temperature data as 'location' in all 4 systems. We restricted data to the years 1980-2015 for all systems in order to get comparable study periods. Moreover, we used only time series with a minimum of $10 \mathrm{yr}$, and when calculating correlation in time series between pairs of locations we excluded pairs with less than $10 \mathrm{yr}$ of overlapping data. This was done to obtain robust

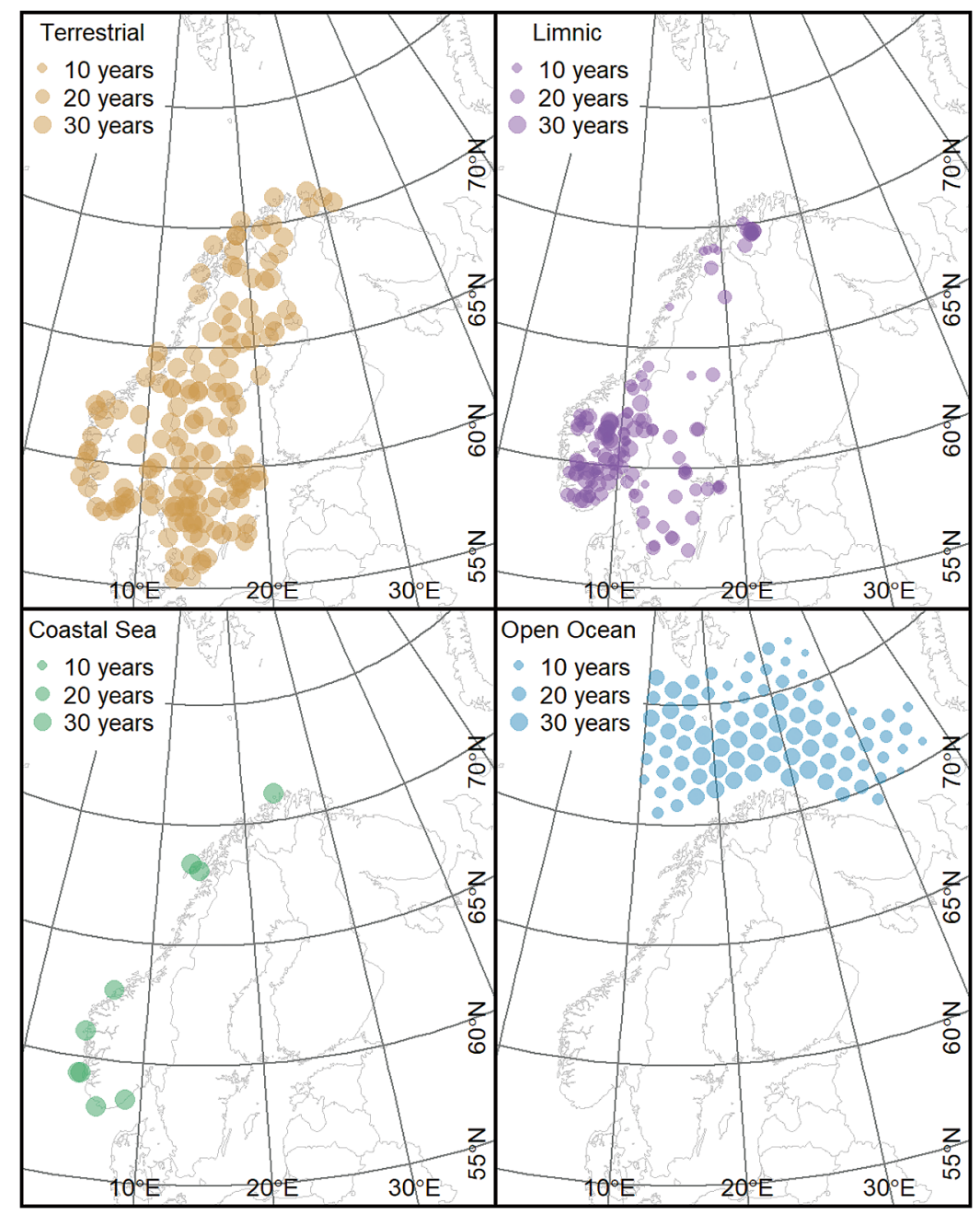

Fig. 1. Locations with temperature data in the 4 systems. The size of the points indicates length of the longest time series at a given location 
estimates of correlations that were not strongly influenced by strong anomalies in a single year.

\subsection{Estimating spatial autocorrelation}

The spatial autocorrelation of seasonal temperatures for a system was described by correlograms based on the spatial pattern of Moran's I based on mean seasonal temperatures over the study period for each location. $I$ was then described as a function of distance between pairs of locations, modelled by a spline function with maximum number of knots $=4$ (Bjørnstad \& Falck 2001). In such correlograms, 0 represents the overall similarity in temperature across all locations within a system. Distances where $I>0$ mean that the locations at these distances are more similar than what would be expected by chance, whereas values $<0$ mean that locations are more dissimilar than what would be expected by a random distribution of the locations in space. The typical spatial pattern is that close locations are more similar than by chance (i.e. Moran's $I>0$ ). The curve that describes the relationship between distance and Moran's $I$ will cross 0 at a distance $D_{I, 0}$, representing the distance for which there is no spatial autocorrelation in the temperature.

\subsection{Estimating spatial synchrony in temperature}

The spatial synchrony in temperature was assessed by calculating the pairwise correlation in the standardised first-order differential of the time series from a system and season (Hansen et al. 2020). For each pair of locations, we get a correlation, $\rho$, and a distance between the locations. Following the approach of Bjørnstad \& Falck (2001), we used a spline function with maximum number of knots $=4$ to describe how the correlation in the dynamics of temperature was related to distance, expecting a decrease in the correlation with increasing distance between locations (Bjørnstad et al. 1999). We calculated the mean correlation among all pairs of stations, $\bar{\rho}$, and based on the spline model, the distance at which the estimated curve crossed $\bar{\rho}, \lambda_{\bar{\rho}}$.

For both the spatial autocorrelation and the synchrony, we ran a bootstrapping procedure $(n=1000)$ by drawing pairs of locations at random and refitting the spline (Bjørnstad \& Falck 2001). We then used the $95 \%$ credible interval (CI) of differences in the bootstrap of 2 systems or seasons to assess the strength of evidence for system-specific or season-specific differences in spatial properties of environmental variation.

\section{RESULTS}

Estimates of $\bar{\rho}$ (and hence $\lambda_{\bar{\rho}}$ ), and to some extent also $D_{I, 0}$, will be affected by the distribution of distances between locations within a given system. For instance, limnic (winter) and open ocean mainly have locations closer than $800 \mathrm{~km}$, i.e. half the range as for terrestrial systems. Accordingly, in limnic and open ocean, $\bar{\rho}$ will be based on only close locations compared to terrestrial, and thus be biased towards higher $\bar{\rho}$ and shorter $\lambda_{\bar{\rho}}$. This can be accounted for by only including pairs of locations that were $<650 \mathrm{~km}$ from each other (see Fig. 3, dotted lines). Below we report the estimates for the complete range for a system; however, the $95 \%$ CIs to assess evidence for differences between systems or seasons are based on pairs of locations closer than $650 \mathrm{~km}$ (e.g. Table 1 and see Table S1 in the Supplement at www.int-res.com/ articles/suppl/cr01641_supp.pdf).

\subsection{Spatial autocorrelation}

There was a strong spatial autocorrelation in terrestrial temperature (Fig. 2), with closer locations being more similar than the average similarity across all stations, and locations far from each other being more dissimilar than expected by chance. This pattern was quite similar for summer and winter (summer $D_{I, 0}=592 \mathrm{~km}$, winter $D_{I, 0}=622 \mathrm{~km}, 95 \%$ CI overlapped 0 , Table 1). The limnic and coastal sea systems had a much weaker spatial structured autocorrelation in temperature compared to the terrestrial system (Fig. 2; Table S1). The coastal sea had a stronger spatial structure during summer, with $D_{I, 0}>750 \mathrm{~km}$ at several depths; however, the uncertainty in these estimates is high due to the rather few spatial locations (Figs. 1 \& 2, Table 1). The open ocean system had a spatial autocorrelation structure similar to the terrestrial, with high positive autocorrelation at short distances and negative autocorrelation at large distances. However, $D_{I, 0}$ was shorter than for the terrestrial system both in summer and winter and for all depths (Fig. 2; Table S1).

\subsection{Synchrony in the dynamics of temperature}

In winter, the spatial synchrony in temperature was considerably higher for the terrestrial system $(\bar{\rho}=$ $0.82)$ than for the 3 aquatic systems $(\bar{\rho}<0.64$, Fig. 3 , all $95 \%$ CI $>0$; Table S1). The limnic systems had the lowest synchrony of all during winter, with $\bar{\rho}<0.17$ at 
Table 1. Seasonal differences in measures of the scale of spatial autocorrelation $\left(D_{I, 0}\right)$, the mean synchrony $\bar{\rho}$ and the spatial scaling of the synchrony $\lambda_{\rho}$ in temperature in the 4 systems. Differences are presented as summer-winter, i.e. positive values mean higher spatial autocorrelation and synchrony in summer than in winter, and are based on bootstrapping $(\mathrm{n}=1000)$ of spline models from pairwise distances (see Bjørnstad \& Falck 2001) for locations $<650 \mathrm{~km}$ for all systems, in order to allow for comparison when the range of distances differs between systems and seasons. Parentheses give the $95 \%$ credible intervals. Bold font highlights intervals that do not contain 0 , suggesting strong evidence for seasonal differences in the spatial property of the environmental variation in system

\begin{tabular}{|c|c|c|c|c|}
\hline System & Depth (m) & $D_{I, 0}(\mathrm{~km})$ & $\bar{\rho}$ & $\lambda_{-}^{-}(\mathrm{km})$ \\
\hline Terrestrial & - & $-37(-157 ; 92)$ & $-0.155(-0.209 ;-0.102)$ & $12(-17 ; 34)$ \\
\hline Limnic & 1 & $251(137 ; 358)$ & $0.200(0.094 ; 0.300)$ & $132(69 ; 190)$ \\
\hline Limnic & 2 & $200(-15 ; 344)$ & $0.298(0.210 ; 0.388)$ & $142(69 ; 207)$ \\
\hline Limnic & 5 & $41(-190 ; 232)$ & $0.053(-0.006 ; 0.106)$ & $157(86 ; 207)$ \\
\hline Limnic & 15 & $97(-169 ; 272)$ & $-0.061(-0.147 ; 0.021)$ & $99(34 ; 172)$ \\
\hline Coastal sea & 1 & $243(-39 ; 539)$ & $-0.001(-0.307 ; 0.324)$ & $94(-207 ; 362)$ \\
\hline Coastal sea & 50 & $31(-409 ; 261)$ & $-0.425(-0.601 ;-0.200)$ & $-19(-259 ; 190)$ \\
\hline Coastal sea & 100 & $-23(-435 ; 154)$ & $-0.061(-0.319 ; 0.160)$ & $14(-310 ; 276)$ \\
\hline Coastal sea & 300 & $-74(-552 ; 160)$ & $-0.053(-0.248 ; 0.148)$ & $24(-310 ; 241)$ \\
\hline Open ocean & 1 & $-10(-141 ; 102)$ & $0.082(-0.021 ; 0.197)$ & $7(-87 ; 103)$ \\
\hline Open ocean & 50 & $17(-120 ; 162)$ & $-0.160(-0.252 ;-0.068)$ & $-60(-190 ; 86)$ \\
\hline Open ocean & 100 & $21(-119 ; 171)$ & $-0.136(-0.236 ;-0.040)$ & $-57(-190 ; 121)$ \\
\hline Open ocean & 300 & $18(-111 ; 141)$ & $-0.023(-0.132 ; 0.087)$ & $-87(-224 ; 17)$ \\
\hline
\end{tabular}

all depths. The coastal sea had winter $\bar{\rho}$ from 0.32 to 0.64 , and the open ocean was quite similar (winter $\bar{\rho}$ from 0.33 to 0.46 ). The terrestrial system had considerably lower $\bar{\rho}$ during summer $(\bar{\rho}=0.66)$ compared to winter (Table 1), but it was still higher than in all the other systems (Fig. 3; Table S1). Of the 4 systems, only the limnic system had consistently higher $\bar{\rho}$ during summer than in winter, particular at the shallowest depths $(\bar{\rho}=0.39$, Fig. 3 , Table 1$)$. Coastal sea had somewhat lower $\bar{\rho}$ during summer $(0.16-0.38)$, as did the open ocean (0.28-0.51, Fig. 3, Table 1).

In all systems and seasons, the general pattern was that the synchrony in temperature decreased with increasing distance between locations (Fig. 3). The terrestrial and coastal sea had the greatest spatial scaling of the 4 systems, both during summer (terrestrial: $\lambda_{\bar{\rho}}=692 \mathrm{~km}$, coastal sea: $\lambda_{\bar{\rho}}=272-620 \mathrm{~km}$ ) and winter (terrestrial: $\lambda_{\bar{\rho}}=670 \mathrm{~km}$, coastal sea: $\lambda_{\bar{\rho}}=432-675 \mathrm{~km}$, Fig. 3). The limnic system had very short spatial scaling during winter $\left(\lambda_{\bar{\rho}}<143 \mathrm{~km}\right)$, including at the 2 greatest depths during summer (Fig. 3). At shallower water and during summer, the spatial scaling was close to that of the terrestrial system $\left(\lambda_{\bar{\rho}}=463\right.$ and $507 \mathrm{~km}$, Fig. 3). Open ocean had quite short spatial scaling at all depths in both season $\left(\lambda_{\bar{\rho}}: 193-388\right.$ km, Fig. 3$)$.

\subsection{Correlation between spatial autocorrelation and spatial synchrony}

The correlation between the scaling of the spatial autocorrelation and the pattern of synchrony was analysed based on pairs with $<650 \mathrm{~km}$ distance to avoid bias due to difference in the extent of the study system. For the terrestrial system during winter, the estimated $D_{I, 0}$ was not estimable because of positive autocorrelation up to $650 \mathrm{~km}$. Accordingly, we set this to $650 \mathrm{~km}$ for the terrestrial system during winter. The correlation between $D_{I, 0}$ and $\lambda_{\bar{\rho}}$ (both variables $\ln$-transformed) was significantly positive when analysed across all seasons and systems $\left(\mathrm{r}^{2}=0.615\right.$, $t=3.82, \mathrm{df}=24, \mathrm{p}=0.001$, Fig. 4). Omitting the coastal system, which had few points and great uncertainties in the measures of spatial structure (e.g. Fig. 2), showed an even stronger positive correlation between $D_{I, 0}$ and $\lambda_{\bar{\rho}}\left(\mathrm{r}^{2}=0.870, t=7.07, \mathrm{df}=16, \mathrm{p}<0.001\right)$. The correlation between $D_{I, 0}$ and $\bar{\rho}$ was significantly positive both when including coastal sea $\left(\mathrm{r}^{2}=0.549, t=\right.$ $3.22, \mathrm{df}=24, \mathrm{p}=0.004)$, and excluding it $\left(\mathrm{r}^{2}=0.803\right.$, $t=5.39, \mathrm{df}=16, \mathrm{p}<0.001$, Fig. 4$). \bar{\rho}$ and $\lambda_{\bar{\rho}}$ were positively correlated when excluding coastal sea $\left(\mathrm{r}^{2}=\right.$ $0.733, t=4.31, \mathrm{df}=16, \mathrm{p}=0.001$ ), but not if coastal sea was included $\left(\mathrm{r}^{2}=0.329, t=1.70, \mathrm{df}=24, \mathrm{p}=\right.$ 0.101 , Fig. 4). These positive correlations suggest that the spatial autocorrelation in temperature to a great extent also reflects the spatial scale of synchrony in temperature.

\section{DISCUSSION}

Ecosystems worldwide and in all biomes face challenges related to human activity (IPBES 2019). This calls for conservation actions in order to maintain 


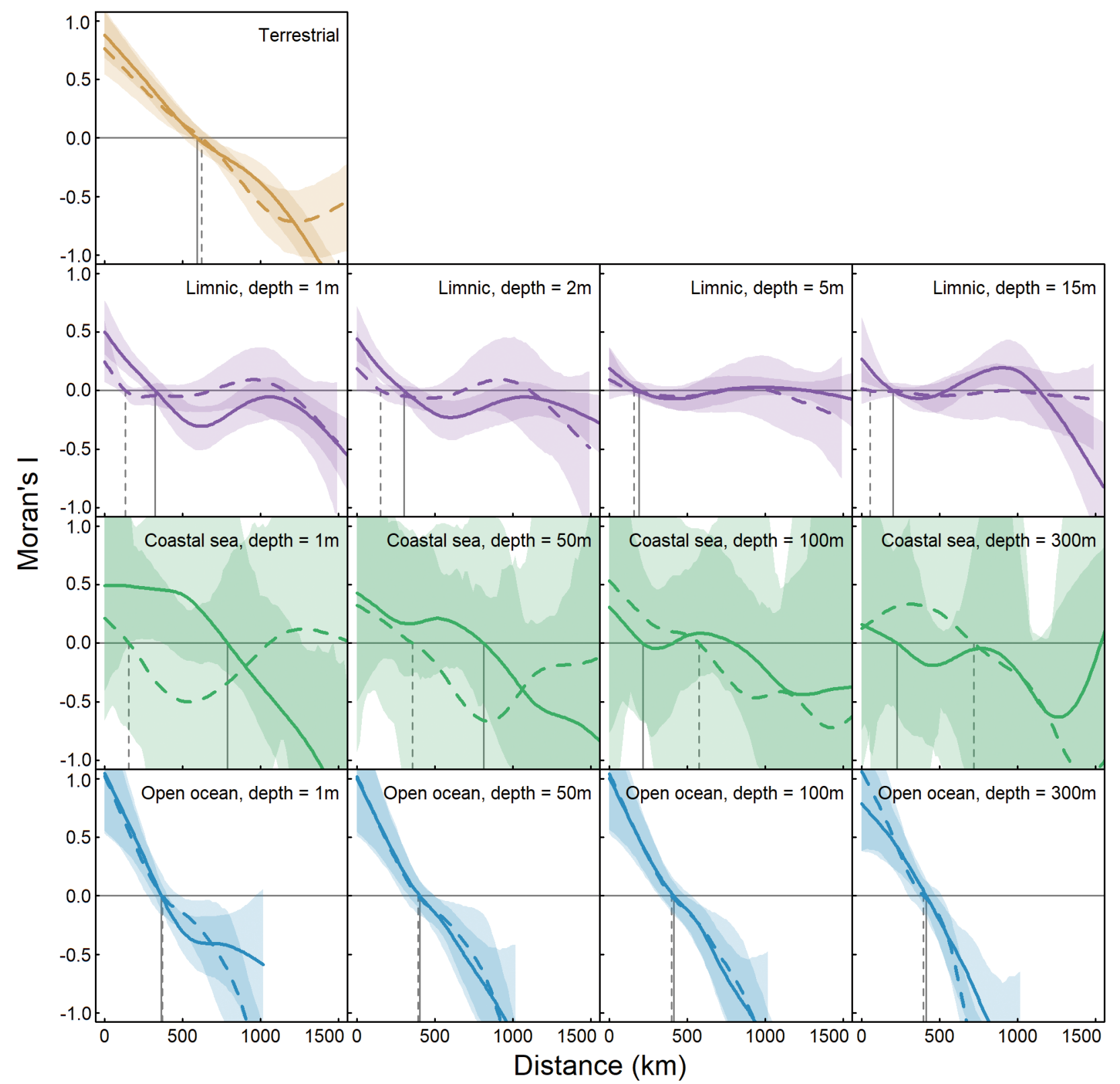

Fig. 2. Spatial autocorrelation in temperature during winter (dashed lines) and summer (solid lines) in 4 systems and at different depths in the aquatic systems. The vertical lines indicate the distance at which the spatial autocorrelation does not deviate from the overall spatial autocorrelation of temperature in the specific system and season, $D_{I, 0}$. The shaded areas give the $95 \%$ confidence interval based on non-parametric bootstrapping $(\mathrm{N}=1000$, Bjørnstad \& Falck 2001)

biodiversity and ecosystem functioning. The physical differences between many systems has raised the question whether it is possible to generalise conservation practices and strategies across systems, for instance between terrestrial and marine systems, which vary greatly with respect to processes such as dispersal distance and movement patterns (Carr et al. 2003, Mokany et al. 2010). Here, we show that the spatial structure of environmental variation also differs among systems. However, our results suggest that the scale of the spatial structure and synchrony is not necessarily greatest in marine systems (e.g. Carr et al. 2003). Temperature in the terrestrial systems had a high autocorrelation over large distances, which to a lesser extent was the case in the ocean systems, but not in the limnic system (Fig. 3).

The generality of our finding relies to some extent on comparable data between systems. For instance, $\bar{\rho}$ was calculated as the mean correlation in the dynamics of temperature of all pairs of locations. For the ter- 


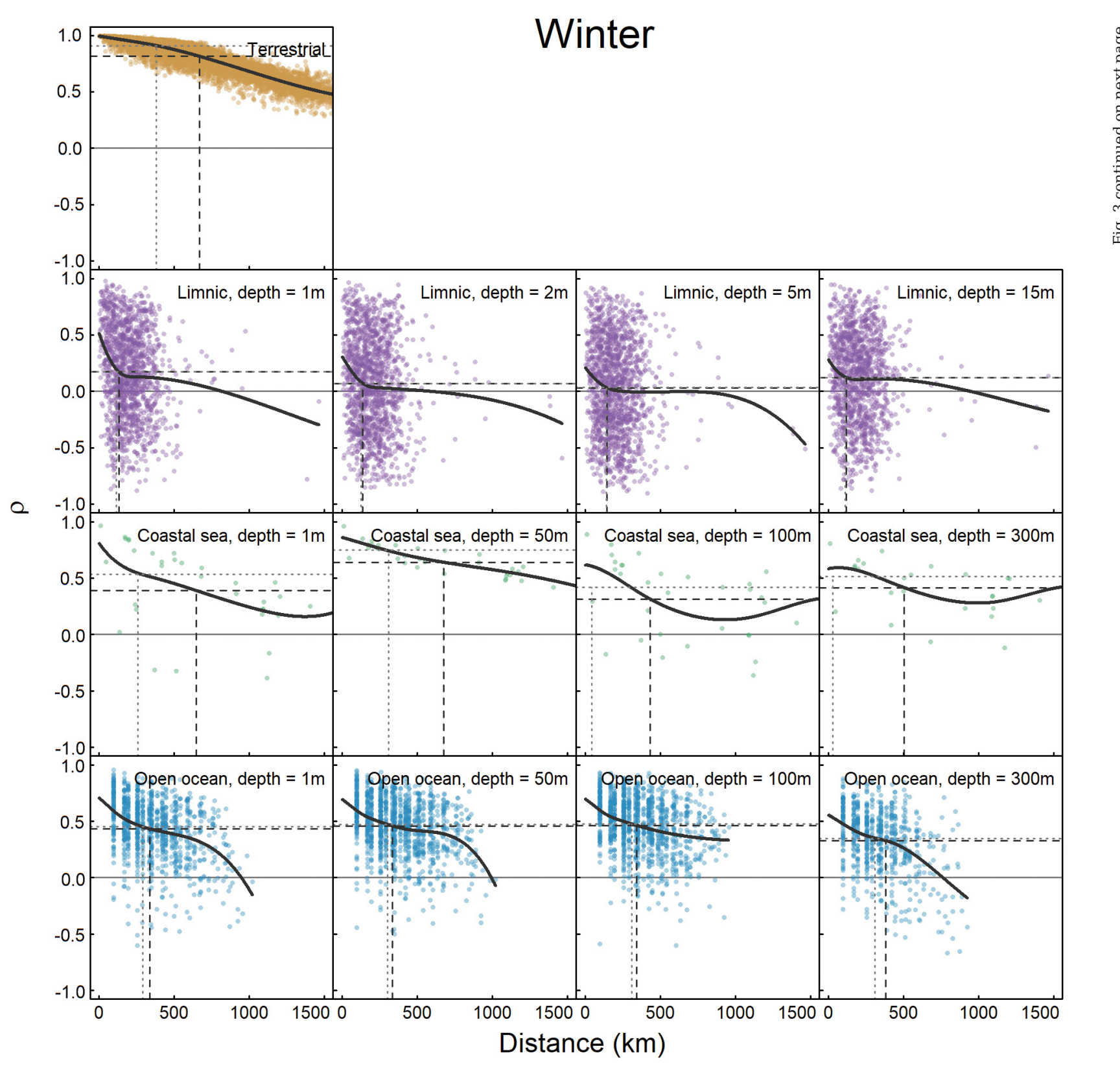

Fig. 3. Spatial synchrony, $\rho$, in temperature in terrestrial, limnic, coastal sea and marine systems (Fig. 1) during winter (February-March) and summer (July-August). In the 3 aquatic systems, temperature was measured at 4 depths. The horizontal dashed lines show the overall mean correlation, $\bar{\rho}$, in the temporal dynamics of temperature across all locations in a system. The vertical dashed lines show $\lambda_{\bar{\rho}}$, the distance at which the predicted relationship between $\rho$ and distance is below $\bar{\rho}$. The light gray dotted lines show $\bar{\rho}$ and $\lambda_{\bar{\rho}}$ based on pairs of locations that are maximum $650 \mathrm{~km}$ from each other

restrial system, the distribution of distance between pairs of locations reached $>1900 \mathrm{~km}$, with a high number of pairs across the range of distances. For the open ocean and limnic system during winter, most locations were $<700 \mathrm{~km}$ from each other. Because environmental correlation is typically higher at short distances, the estimate of $\bar{\rho}$ for systems where we had data over larger areas, such as the terrestrial and limnic systems during summer, will be underesti- mated compared to systems with shorter distances between pairs (Hansen et al. 2020). However, accounting for such a bias by calculating $\bar{\rho}$ and $\lambda_{\bar{\rho}}$ by using a similar maximum distance (e.g. $650 \mathrm{~km}$ ) between pairs for all systems still showed the largest spatial scale and highest synchrony in the variation in temperature in the terrestrial system.

The variation in temperature differed greatly between systems. In some terrestrial locations, the 




Fig. 3 (continued)

range in winter temperature was $>14^{\circ} \mathrm{C}$ during the study period, which will never occur in the aquatic system during any season, at least not at greater depths. However, organisms are adapted to temperature ranges occurring in their environments (Clarke 2017, Gvoždík 2018), which is more narrow in marine and limnic compared to most terrestrial systems. In the context of temporal variation in temperatures and how this is synchronised among locations, we believe that the standardised variation around the mean is most appropriate for understanding the spatiotemporal properties of environmental variation across sys- tems, because these values to a large extent determine the thermally viable envelopes for species (Deutsch et al. 2008, Tewksbury et al. 2008).

Spatial heterogeneity in environmental fluctuations is central for local and regional extinction probability both from classic meta-population theory (Hanski \& Gilpin 1996) as well as more recent models of spatial ecology (Heino et al. 1997, Engen \& Sæther 2005, 2016). The basic concept is that if environmental conditions synchronise populations over large distances, the likelihood that all populations experience periods of critical low population sizes at the same 

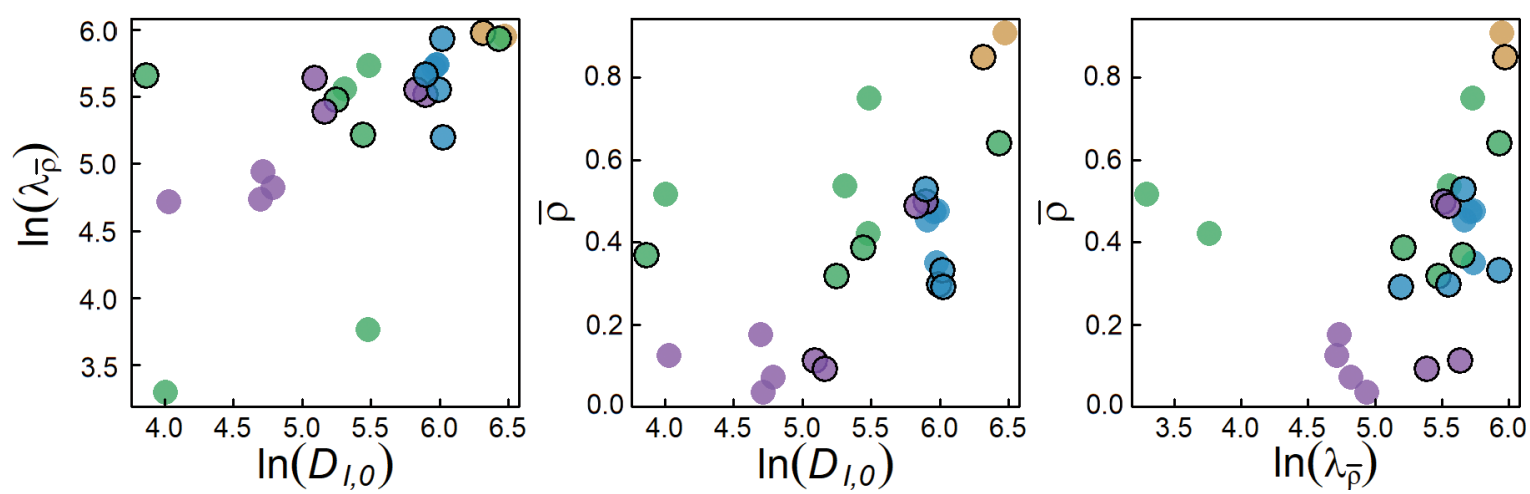

Fig. 4. Correlation plots between system-specific measures of spatial patterns of autocorrelation. $D_{I, 0}$ is the distance at which the spatial autocorrelation in temperature becomes similar to the overall mean similarity based on Moran's $I$. $\bar{\rho}$ is the overall synchrony in the temperature dynamics in the system, and $\lambda_{\rho}$ is the distance at which the predicted relationship between distance and synchrony, $\rho$, decreases below $\bar{\rho}$. Colours represent systems: orange $=$ terrestrial, purple $=$ limnic, green $=$ coastal sea, blue $=$ open ocean. Symbols with black outline are winter, symbols with no outline are summer. Note that $D_{I, 0}$ and $\lambda_{\bar{\rho}}$ are ln-transformed. To allow comparisons across systems with different spatial extent, only pairs of locations closer than $650 \mathrm{~km}$ were used in the estimation of the 3 parameters

time increases (Heino et al. 1997). In periods of small population sizes, the negative influence of demographic stochasticity on population growth increases, and so do the loss of genetic variation and dispersal rates. Such negative feedback may drive the species into a negative vortex ending with local and regional extinction (Amarasekare 1998, Tack et al. 2015). High environmental synchrony may cause such processes to occur over large areas simultaneously, which reduces the likelihood for a local rescue effect by immigration from neighbouring populations. Such processes can be scaled up to communities (Hansen et al. 2013, Koenig \& Liebhold 2016), where spatiotemporal environmental variation affects the spatial patterns of fluctuations in species composition or richness (Mutshinda et al. 2009, Grøtan et al. 2012, Bellier et al. 2014).

Species differ in their sensitivity to environmental conditions, and this has been used to explain variation in population synchrony among species with contrasting life histories (Marquez et al. 2019). Another striking consequence of life history variation, for instance along the fast-slow continuum (Oli 2004, Bjørkvoll et al. 2012), is that the sensitivity of population dynamics to different life history stages varies among species, and these life history stages often occur during different periods of the year. Our results suggest that seasonal variation in environmental synchrony can cause patterns of spatial scaling properties of species dynamics because the Moran effect is stronger when the environment is more synchronised (Moran 1953, Royama 1992, Hansen et al. 2020, Herfindal et al. 2020). In the terrestrial system, this occurs during winter, whereas, for instance, the limnic system has a higher synchrony in summer (Fig. 3, Table 1). However, few studies have assessed to what extent seasonal variation in environmental synchrony can explain speciesspecific patterns of population synchrony (but see Herfindal et al. 2020 for an example on synchrony in life history traits). Here, comparative studies between systems that differ in the seasonal patterns of synchrony (e.g. marine vs. terrestrial systems, Fig. 3) may shed light onto the relative importance of species demography and environmental variation in time and space for the spatial scaling of population dynamics.

We believe that our results give some indications of the spatial scale at which the conservation of populations and ecosystems may occur given the environmental condition in time and space affecting stochastic processes in populations and communities. This does not mean that other characteristics, such as dispersal capacity or nutrient flow, are not important (Mokany et al. 2010). However, stochastic processes must also be considered in practical conservation planning, even if modelling such processes in time and space on species or communities may be challenging. Assessing the patterns of the major driver of such processes, i.e. the environmental variation in time and space, may be one step to understand the relative importance of these processes across ecosystems. This is particularly true in the face of the ongoing global changes in climate, habitats or other important drivers. Although there are quite clear predictions about the temporal patterns of climate change, less is known about how climate change affects the spatial structure of the environment (but 
see Koenig \& Liebhold 2016). If the spatial structure of the environment changes, so must our conservation and management of nature. It is thus pivotal to acknowledge the spatial properties of environmental variation.

Acknowledgements. In addition to financial support from the Research Council of Norway (RCN) to the project Sustain (project no. 244647), research was supported through the RCN Centres of Excellence funding scheme (project no. 223257).

\section{LITERATURE CITED}

Amarasekare P (1998) Allee effects in metapopulation dynamics. Am Nat 152:298-302

Aure J, Østensen Ø (1993) Hydrographical normals and long-term variations in Norwegian coastal waters from 1936 to 1992. Fisken Havet 6:1-75

* Bellier E, Grøtan V, Engen S, Schartau AK, Herfindal I, Finstad AG (2014) Distance decay of similarity, effects of environmental noise and ecological heterogeneity among species in the spatio-temporal dynamics of a dispersallimited community. Ecography 37:172-182

* Bjørkvoll E, Grøtan V, Aanes S, Sæther BE, Engen S, Aanes R (2012) Stochastic population dynamics and life-history variation in marine fish species. Am Nat 180:372-387

Bjørnstad ON, Falck W (2001) Nonparametric spatial covariance functions: estimation and testing. Environ Ecol Stat 8:53-70

Bjørnstad ON, Ims RA, Lambin X (1999) Spatial population dynamics: analyzing patterns and processes of population synchrony. Trends Ecol Evol 14:427-432

Brennan SR, Schindler DE, Cline TJ, Walsworth TE, Buck G, Fernandez DP (2019) Shifting habitat mosaics and fish production across river basins. Science 364:783-786

Brondizio ES, Settele J, Díaz S, Ngo HT (eds) (2019) Global assessment report on biodiversity and ecosystem services of the Intergovernmental Science-Policy Platform on Biodiversity and Ecosystem Services. IPBES Secretariat, Bonn

Carr MH, Neigel JE, Estes JA, Andelman S, Warner RR, Largier JL (2003) Comparing marine and terrestrial ecosystems: implications for the design of coastal marine reserves. Ecol Appl 13:90-107

Clarke A (2017) Principles of thermal ecology: temperature, energy, and life. Oxford University Press, Oxford

Cole J, Lovett G, Findlay S (eds) (1991) Comparative analyses of ecosystems: patterns, mechanisms, and theories. Springer, New York, NY

Dembkowski DJ, Willis DW, Wuellner MR (2016) Synchrony in larval yellow perch abundance: the influence of the Moran Effect during early life history. Can J Fish Aquat Sci 73:1567-1574

*Deutsch CA, Tewksbury JJ, Huey RB, Sheldon KS, Ghalambor CK, Haak DC, Martin PR (2008) Impacts of climate warming on terrestrial ectotherms across latitude. Proc Natl Acad Sci USA 105:6668-6672

Elton CS (1924) Periodic fluctuations in the numbers of animals: their causes and effects. J Exp Biol 2:119-163

Engen S, Sæther BE (2005) Generalizations of the Moran effect explaining spatial synchrony in population fluctuations. Am Nat 166:603-612
Engen S, Sæther BE (2016) Spatial synchrony in population dynamics: the effects of demographic stochasticity and density regulation with a spatial scale. Math Biosci 274: $17-24$

Frank K (2005) Metapopulation persistence in heterogeneous landscapes: lessons about the effect of stochasticity. Am Nat 165:374-388

Frank KT, Petrie B, Leggett WC, Boyce DG (2016) Large scale, synchronous variability of marine fish populations driven by commercial exploitation. Proc Natl Acad Sci USA 113:8248-8253

* Grøtan V, Lande R, Engen S, Sæther BE, DeVries PJ (2012) Seasonal cycles of species diversity and similarity in a tropical butterfly community. J Anim Ecol 81:714-723

*Gvoždík L (2018) Just what is the thermal niche? Oikos 127 : 1701-1710

Hansen BB, Grøtan V, Aanes R, Sæether BE and others (2013) Climate events synchronize the dynamics of a resident vertebrate community in the High Arctic. Science 339: 313-315

Hansen BB, Grøtan V, Herfindal I, Lee AM (2020) The Moran effect revisited: spatial population synchrony under global warming. Ecography 43:1591-1602

Hanski I, Gilpin M (1996) Metapopulation biology: ecology, genetics and evolution. Academic Press, London

*Heino M, Kaitala V, Ranta E, Lindström J (1997) Synchronous dynamics and rates of extinction in spatially structured populations. Proc R Soc B 264:481-486

Herfindal I, Tveraa T, Stien A, Solberg EJ, Grøtan V (2020) When does weather synchronize life history traits? Spatiotemporal patterns in juvenile body mass of two ungulates. J Anim Ecol 89:1419-1432

IPBES (2019) Summary for policymakers of the global assessment report on biodiversity and ecosystem services of the Intergovernmental Science-Policy Platform on Biodiversity and Ecosystem Services. IPBES Secretariat, Bonn

Jakobsen T, Korsbrekke K, Mehl S, Nakken O (1997) Norwegian combined acoustic and bottom trawl surveys for demersal fish in the Barents sea during winter. ICES CM 17

Jones J, Doran PJ, Holmes RT (2003) Climate and food synchronize regional forest bird abundances. Ecology 84: 3024-3032

KKlein Tank AMG, Wijngaard JB, Können GP, Böhm R and others (2002) Daily dataset of 20th-century surface air temperature and precipitation series for the European Climate Assessment. Int J Climatol 22:1441-1453

Knapp S, Schweiger O, Kraberg A, Asmus H and others (2017) Do drivers of biodiversity change differ in importance across marine and terrestrial systems - or is it just different research communities' perspectives? Sci Total Environ 574:191-203

Koenig WD, Liebhold AM (2016) Temporally increasing spatial synchrony of North American temperature and bird populations. Nat Clim Change 6:614-617

KLiebhold A, Koenig WD, Bjørnstad ON (2004) Spatial synchrony in population dynamics. Annu Rev Ecol Evol Syst 35:467-490

*Marquez JF, Lee AM, Aanes S, Engen S, Herfindal I, Salthaug A, Sæther BE (2019) Spatial scaling of population synchrony in marine fish depends on their life history. Ecol Lett 22:1787-1796

*Mayr E (1954) Geographic speciation in tropical echinoids. Evolution 8:1-18 
Messié M, Chavez FP (2012) A global analysis of ENSO synchrony: the oceans' biological response to physical forcing. J Geophys Res 117(C9):C09001

Mokany K, Richardson AJ, Poloczanska ES, Ferrier S (2010) Uniting marine and terrestrial modelling of biodiversity under climate change. Trends Ecol Evol 25:550-551

Moore JW, McClure M, Rogers LA, Schindler DE (2010) Synchronization and portfolio performance of threatened salmon. Conserv Lett 3:340-348

Moran PAP (1953) The statistical analysis of the Canadian lynx cycle. II. Synchronization and meteorology. Aust J Zool 1:291-298

Mutshinda CM, O'Hara RB, Woiwod IP (2009) What drives community dynamics? Proc R Soc B 276:2923-2929

Myers RA, Mertz G, Bridson J (1997) Spatial scales of interannual recruitment variations of marine, anadromous, and freshwater fish. Can J Fish Aquat Sci 54:1400-1407

Oli MK (2004) The fast-slow continuum and mammalian life-history patterns: an empirical evaluation. Basic Appl Ecol 5:449-463

Olsen E, Aanes S, Mehl S, Holst JC, Aglen A, Gjøsæeter H (2010) Cod, haddock, saithe, herring, and capelin in the Barents Sea and adjacent waters: a review of the biological value of the area. ICES J Mar Sci 67:87-101

Post E, Forchhammer MC (2002) Synchronization of animal population dynamics by large-scale climate. Nature 420 : 168-171

Powell TM, Steele JH (eds) (1995) Ecological time series. Chapman \& Hall, New York, NY

Royama T (1992) Analytical population dynamics. Chapman \& Hall, London

Sæather BE, Ringsby TH, Røskaft E (1996) Life history variation, population processes and priorities in species conservation: towards a reunion of research paradigms. Oikos 77:217-226

Editorial responsibility: Tim Sparks, Poznań, Poland

Reviewed by: 2 anonymous referees
Sæther BE, Coulson T, Grøtan V, Engen S and others (2013) How life history influences population dynamics in fluctuating environments. Am Nat 182:743-759

Sætre R, Aure J, Danielssen DS (2003) Long-term hydrographic variability patterns off the Norwegian coast and in the Skagerrak. ICES Mar ScI Symp 219:150-159

Steele JH (1985) A comparison of terrestrial and marine ecological systems. Nature 313:355-358

* Steele JH (1991) Can ecological theory cross the land-sea boundary? J Theor Biol 153:425-436

Steele JH, Henderson EW (1994) Coupling between physical and biological scales. Philos Trans R Soc B 343:5-9

Steen H, Ims RA, Sonerud GA (1996) Spatial and temporal patterns of small-rodent population dynamics at a regional scale. Ecology 77:2365-2372

Stenseth NC, Chan KS, Tong H, Boonstra R and others (1999) Common dynamic structure of Canada lynx populations within three climatic regions. Science 285: 1071-1073

Stiansen JE, Filin AA (eds) (2007) Joint PINRO/IMR report on the state of the Barents Sea ecosystem 2006, with expected situation and considerations for management. IMR/PINRO Joint Report Series No. 2/2007. Institute of Marine Research, Bergen

* Tack AJM, Mononen T, Hanski I (2015) Increasing frequency of low summer precipitation synchronizes dynamics and compromises metapopulation stability in the Glanville fritillary butterfly. Proc R Soc B 282:20150173

Tewksbury JJ, Huey RB, Deutsch CA (2008) Ecology. Putting the heat on tropical animals. Science 320:1296-1297

Vasseur DA, Yodzis P (2004) The color of environmental noise. Ecology 85:1146-1152

*Walter JA, Sheppard LW, Anderson TL, Kastens JH, Bjørnstad ON, Liebhold AM, Reuman DC (2017) The geography of spatial synchrony. Ecol Lett 20:801-814

Submitted: September 14, 2020

Accepted: February 8, 2021

Proofs received from author(s): June 4, 2021 